\title{
The role of gene polymorphisms in endometriosis
}

\author{
MICHAIL MATALLIOTAKIS ${ }^{1,2}$, MARIA I. ZERVOU ${ }^{2}$, CHAROULA MATALLIOTAKI $^{1}$, NILUFER RAHMIOGLU ${ }^{3,4}$, \\ GEORGE KOUMANTAKIS ${ }^{5}$, IOANNIS KALOGIANNIDIS ${ }^{6}$, IOANNIS PRAPAS ${ }^{7}$, KRINA ZONDERVAN $^{3,4}$, \\ DEMETRIOS A. SPANDIDOS ${ }^{8}$, IOANNIS MATALLIOTAKIS ${ }^{1}$ and GEORGE N. GOULIELMOS ${ }^{2}$
}

\author{
${ }^{1}$ Department of Obstetrics and Gynecology, Venizeleio General Hospital, Heraklion 714 09; ${ }^{2}$ Section of Molecular Pathology \\ and Human Genetics, Department of Internal Medicine, School of Medicine, University of Crete, Heraklion 71003 , \\ Crete, Greece; ${ }^{3}$ Wellcome Trust Centre for Human Genetics University of Oxford, Oxford OX1 1JD; ${ }^{4}$ Endometriosis \\ CaRe Centre, Nuffield Department of Obstetrics and Gynaecology, University of Oxford, Oxford OX3 7BN, UK; \\ ${ }^{5}$ Genesis Athens Clinic, Athens $15232 ;{ }^{6}$ rd Department of Obstetrics and Gynaecology, Aristotle University \\ of Thessaloniki, Thessaloniki $54124 ;{ }^{7}$ IAKENTRO, Infertility Treatment Center, Thessaloniki 542 50; \\ ${ }^{8}$ Laboratory of Clinical Virology, Medical School, University of Crete, Heraklion 710 03, Crete, Greece
}

Received July 21, 2017; Accepted August 29, 2017

DOI: $10.3892 / \mathrm{mmr} .2017 .7398$

\begin{abstract}
Endometriosis is a benign gynecologic disorder, affecting up to $10 \%$ of women, characterized by the presence of functional endometrial tissue at ectopic positions generally within the peritoneum. It is a heritable condition influenced by multiple genetic and environmental factors, with an overall heritability estimated at approximately $50 \%$. In this study, we investigated whether single nucleotide polymorphisms (SNPs) rs7521902, rs10859871 and rs11031006, mapping to WNT4, VEZT and FSHB genetic loci, respectively, are associated with risk for endometriosis in a Greek population. This study included 166 women with histologically confirmed endometriosis diagnosed through surgery and 150 normal controls. Genotyping of the rs7521902, rs10859871 and rs11031006 SNPs was performed with Taqman primer/probe sets. A significant association was detected with the AC genotype of rs7521902 (WNT4) in patients with stage III and IV disease only. Evidence for association with endometriosis was also found for the AC genotype of the rs10859871 of VEZT. Notably, a significant difference in the distribution of the AG genotype and the minor allele A of FSHB rs11031006 SNP was found between the endometriosis patients and controls. We found a genetic association between rs11031006 (FSHB) SNP and endometriosis. WNT4 and VEZT genes constitute the most consistently associated genes with endometriosis. In the present study, an association of rs7521902 (WNT4) and rs10859871 (VEZT) was confirmed in women with endometriosis at the genotypic but not the allelic level.
\end{abstract}

Correspondence to: Dr George N. Goulielmos, Section of Molecular Pathology and Human Genetics, Department of Internal Medicine, School of Medicine, University of Crete, Voutes, Heraklion 710 03, Crete, Greece

E-mail: goulielmos@med.uoc.gr

Key words: endometriosis, genetic association, single nucleotide polymorphisms

\section{Introduction}

Endometriosis is a chronic, estrogen-dependent inflammatory, heritable, common gynecological condition by growth of endometrial tissue in sites other than the uterine cavity, most commonly in the pelvic cavity, including the ovaries, the uterosacral ligaments, and pouch of Douglas (1). Endometriosis affects up to $10 \%$ of reproductive-aged women (2), but with varying symptoms, delayed diagnosis and misdiagnosis, the true prevalence of endometriosis is unknown. Susceptibility to endometriosis is known to be influenced by genetic factors (3-7), with heritability to have been estimated at approximately $50 \%$ from twin studies $(8,9)$. A strong familial aggregation has also been reported in a large pedigree of non-human primates (10).

Multiple factors are thought to be involved in the development of endometriosis including genetic and environmental ones, although the exact genomic basis of endometriosis is not yet clear and the exact etiopathogenic mechanism of endometriosis remains to be determined. Currently, the most accepted theory seems to be Sampson's retrograde menstruation hypothesis, which suggests that during menstruation, endometrial fragments migrate through fallopian tubes and reach the peritoneum, as they are able to attach, survive, and implant at different locations (11).

Numerous candidate genes are involved initially in the pathogenesis of endometriosis, including genes involved in inflammation, cell cycle regulation, growth factors, hormone receptors and adhesion molecules (12). However, results from those studies have conflicting results and absence of replication in independent populations. Genome-wide association studies (GWAS) and meta-analyses have led to the identification of disease-risk loci that alter a woman's risk of developing the disorder and provide new insights into potential pathways leading to endometriosis. At present, 19 independent single nucleotide polymorphisms (SNPs) have been robustly associated with endometriosis explaining $5.19 \%$ of the disease variance (13). Of note, the number of these loci is increasing 
as the proportion of cases analyzed are limited to more severe disease stages (stage III/IV endometriosis) rather than stage I/II, thus indicating that moderate to severe endometriosis cases have greater genetic burden relative to minimal or mild disease $(14,15)$. All the identified genome-wide significant loci are located in either intronic (non-coding) regions of genes or intergenic regions. The roles of these variants in the regulation of the expression of target genes has yet to be identified (16). A meta-analysis based on GWAS as well as replication datasets (14) provided evidence for the genome-wide significant association of six loci including rs7521902 (near WNT4) and rs10859871 (near VEZT). These results were confirmed by a recent meta-analysis conducted by Sapkota et $\mathrm{al}$, which, additionally, identified rs11031006 of the FSHB gene as a novel endometriosis-associated SNP (13).

It is known that there are population differences for endometriosis in terms of genetic susceptibility and disease manifestations. Thus, genetic studies reported that some specific genotypes are associated with endometriosis in selective populations, such as Brazil, Turkey and Taiwan (17-20). Accumulating evidence indicates that ethnic heterogeneity of genetic risk factors exists for various complex disorders in Greece such as systemic lupus erythematosus (SLE) $(21,22)$, juvenile idiopathic arthritis (JIA) (23), and rheumatoid arthritis (RA) (24,25). Therefore, ethnic-specific association studies provide novel evidence that can confirm previously reported genetic associations in different populations or question their direct associative role.

The aim of the present study was to identify an association of rs7521902 SNP located $21 \mathrm{~kb}$ downstream of wingless-type MMTV integration site family member 4 (WNT4), VEZT rs10859871 SNP located $17 \mathrm{~kb}$ upstream of the VEZT gene and $F S H B$ rs11031006 SNP located in the 5' region of FSHB with overall endometriosis as well as with the severe stages (ASRM III-IV) of this condition in a Greek population.

\section{Patients and methods}

Patient population and study design. In this case control association study, 316 women were enrolled (166 endometriosis patients and 150 controls) followed in the Department of Obstetrics and Gynecology of Venizeleion Hospital of Heraklion (Heraklion, Greece). The average age of the Greek endometriosis and control cohorts was 32.25 \pm 7.1 and $29.49 \pm 6.7$ years, respectively. The women with endometriosis were diagnosed surgically (laparotomy or laparoscopy), and the disease was confirmed histologically from biopsies. Staging of the disease was performed according to the revised American Fertility Society classification (26). All the members of the control group had given birth to 2-5 (2.3 \pm 0.6$)$ children and had no previous medical record of chronic pelvic pain, dysmenorrhea, or dyspareunia. Both cases and controls were unrelated, living in the same urban environment and came from the same Greek population. All the subjects were of self-reported Greek origin. The study was performed in the Section of Molecular Pathology and Human Genetics of the Medical School of Crete, after obtaining the approval of the Research Committee of the Venizeleion Hospital of Heraklion and was carried out in compliance with the declaration of Helsinki for Medical Research involving human subjects.
Genotyping. Whole blood was collected preoperatively in ethylenediaminetetraacetic acid (EDTA)-containing tubes. Genomic DNA was isolated from peripheral blood leukocytes by using the commercial kit (PureLink ${ }^{\circledR}$ Genomic DNA Mini kit; Invitrogen; Thermo Fisher Scientific, Inc., Waltham, MA, USA) according to the manufacturer's instructions. The extracted DNA was stored at $-20^{\circ} \mathrm{C}$ until analyzed. Allelic discrimination of WNT4 rs7521902, VEZT rs10859871 and FSHB rs11031006 SNPs was carried out using pre-made TaqMan SNP Genotyping assays from Applied Biosystems (Foster City, CA, USA), according to the Applied Biosystems protocol (cat. nos. C_30192951_10, C_30917499_10 and C_32036787_10 for rs7521902, rs10859871 and rs11031006, respectively). A 96-well plate was prepared with a mixture on an Applied Biosystems ViiA ${ }^{\mathrm{TM}} 7$ Real-Time PCR system of 1X TaqMan SNP Genotyping assay, 1X TaqMan Universal Master mix (both from Applied Biosystems) and 20 ng DNA per well. The PCR conditions were denaturation at $95^{\circ} \mathrm{C}$ for $10 \mathrm{~min}$, followed by 40 cycles of $95^{\circ} \mathrm{C}$ denaturation for $15 \mathrm{sec}$ and a $60^{\circ} \mathrm{C}$ annealing for $1 \mathrm{~min}$. After PCR, the plates were read, and the data analysed using Quant Studio ${ }^{\mathrm{TM}}$ Real-Time PCR Software (Applied Biosystems). Allelic discrimination plots were all reviewed individually for quality. Each assay was run with negative controls. For quality control, a random $10 \%$ of the samples were amplified twice to ensure accuracy of the results, with the reproducibility rate being $100 \%$. The genotyping success for all the SNPs analyzed was $>98 \%$.

Statistical analysis. The cases and controls used in the analysis were unrelated. Statistical analysis was performed with the GraphPad Prism statistical program (GraphPad Software, San Diego, CA, USA), by applying the additive model. The Chi-square $\left(\chi^{2}\right)$ test, with one or two degrees of freedom or Fisher's exact test was used to examine differences of genotype and allele frequencies between patients and controls, where all the SNPs had a call rate of $>98 \%$. A two tailed $\mathrm{P}<0.05$ was defined as statistically significant. Odds ratios (OR) and $95 \%$ confidence intervals (CI) were calculated. The genetic variants under investigation were evaluated for deviation from Hardy-Weinberg equilibrium (HWE) by comparing observed and expected genotype frequencies by means of the $\chi^{2}$ test or Fisher's exact test in the control groups (using the program named 'Calculate'; Copyright TRG, SR, INMD, 2008). The distribution of genotypes in the case group for all the three SNPs examined were found to be under HWE $(\mathrm{P}>0.01)$.

\section{Results}

The rs7521902 WNT4 SNP. The patients with endometriosis did not present any increase in genotypic or allelic frequencies compared with the controls $(\mathrm{P}=0.36, \mathrm{OR}=0.52,95 \% \mathrm{CI}$, 0.16-1.71 and $\mathrm{P}=0.16, \mathrm{OR}=1.37,95 \% \mathrm{CI}, 0.89-2.11$ for $\mathrm{AA}$ and $A$, respectively) (Table I), apart from previous findings in other ethnic populations, which reported allele A of rs7521902 as a risk allele for endometriosis (27). However, when patients were analyzed according to the severity of the disease, a significant association was detected regarding the AC genotype of rs7521902 in patients with stage III/IV of the disease $(\mathrm{P}=0.0359, \mathrm{OR}=1.96,95 \% \mathrm{CI}, 1.06-3.59)$ (Table II). 
Table I. Genotype and allele frequencies of the WNT4 rs7521902 polymorphism analyzed in 166 women with endometriosis and 150 healthy controls.

\begin{tabular}{|c|c|c|c|c|}
\hline Genotypes/Alleles & Endometriosis & Controls & P-value & OR $(95 \% \mathrm{CI})$ \\
\hline Genotypes & $\mathrm{N}=166$ & $\mathrm{~N}=150$ & & \\
\hline $\mathrm{CC}$ & $111(66.87 \%)$ & $113(75.33 \%)$ & & 1.00 (Reference) \\
\hline $\mathrm{AC}$ & $49(29.52 \%)$ & $30(20.00 \%)$ & 0.066 & $1.66(0.98-2.80)$ \\
\hline $\mathrm{AA}$ & $6(3.61 \%)$ & $7(4.67 \%)$ & 0.36 & $0.52(0.16-1.71)$ \\
\hline Alleles & $\mathrm{N}=332$ & $\mathrm{~N}=300$ & & \\
\hline $\mathrm{C}$ & $271(81.63 \%)$ & $256(85.33 \%)$ & & 1.00 (Reference) \\
\hline A & $61(18.37 \%)$ & $44(14.67 \%)$ & 0.16 & $1.37(0.89-2.11)$ \\
\hline
\end{tabular}

OR, odds ratio; CI, confidence interval.

Table II. Genotype and allele frequencies of the WNT4 rs7521902 polymorphism analyzed in 79 women with endometriosis (stage III and IV) and 150 healthy controls.

\begin{tabular}{|c|c|c|c|c|}
\hline Genotypes/Alleles & Endometriosis & Controls & P-value & OR $(95 \% \mathrm{CI})$ \\
\hline Genotypes & $\mathrm{N}=79$ & $\mathrm{~N}=150$ & & \\
\hline $\mathrm{CC}$ & $50(63.3 \%)$ & $113(75.3 \%)$ & & 1.00 (Reference) \\
\hline $\mathrm{AC}$ & $26(32,0 \%)$ & $30(20.0 \%)$ & 0.0359 & $1.96(1.06-3.59)$ \\
\hline $\mathrm{AA}$ & $3(3.8 \%)$ & $7(4.7 \%)$ & 0.49 & $0.96(0.24-3.90)$ \\
\hline Alleles & $\mathrm{N}=158$ & $\mathrm{~N}=300$ & & \\
\hline $\mathrm{C}$ & $126(79.8 \%)$ & $256(85.3 \%)$ & & 1.00 (Reference) \\
\hline A & $32(20.3 \%)$ & $44(14.7 \%)$ & 0.11 & $1.55(0.93-2.57)$ \\
\hline
\end{tabular}

OR, odds ratio; CI, confidence interval. Bold, statistically significant difference.

Table III. Genotype and allele frequencies of the VEZT rs 10859871 polymorphism analyzed in 166 women with endometriosis and 150 healthy controls.

\begin{tabular}{|c|c|c|c|c|}
\hline Genotypes/Alleles & Endometriosis & Controls & P-value & OR $(95 \% \mathrm{CI})$ \\
\hline Genotypes & $\mathrm{N}=166$ & $\mathrm{~N}=150$ & & \\
\hline AA & $60(36.1 \%)$ & $53(35.3 \%)$ & 0.07 & $0.49(0.23-1.04)$ \\
\hline $\mathrm{AC}$ & $76(45.8 \%)$ & $84(56.0 \%)$ & 0.01 & $0.39(0.19-0.81)$ \\
\hline $\mathrm{CC}$ & $30(18.1 \%)$ & $13(8.7 \%)$ & & 1.00 (Reference) \\
\hline Alleles & $\mathrm{N}=332$ & $\mathrm{~N}=300$ & & \\
\hline A & $196(59.0 \%)$ & $190(63.3 \%)$ & 0.25 & $0.82(0.6-1.13)$ \\
\hline $\mathrm{C}$ & $136(41.0 \%)$ & $110(36.7 \%)$ & & 1.00 (Reference) \\
\hline
\end{tabular}

OR, odds ratio; CI, confidence interval. Bold, statistically significant difference

The rs 10859871 VEZT SNP. In the case of VEZT rs10859871 SNP, a statistical significant difference was found in the frequency of $\mathrm{AC}$ genotype in patients and controls $(\mathrm{P}=0.01$, $\mathrm{OR}=0.39$, 95\% CI, 0.19-0.81) (Table III). Additionally, irrespective of the small sample size, in an analysis conducted on endometriosis stage, evidence for association with the endometriosis cases stratified uniquely to stages I or III was found for the same (AC) genotype of the rs10859871 $(\mathrm{P}=0.0024$, $\mathrm{OR}=0.20,95 \% \mathrm{CI}, 0.07-0.55$ and $\mathrm{P}=0.049, \mathrm{OR}=0.31,95 \% \mathrm{CI}$, 0.1-0.91, respectively) (data not shown). We did not find evidence for a significant difference between endometriosis patients stages III/IV and controls for genotype or allele frequencies of rs10859871 $(\mathrm{P}=0.16, \mathrm{OR}=0.51,95 \% \mathrm{CI}, 0.29-1.28$ and $\mathrm{P}=0.26$, $\mathrm{OR}=0.79,95 \% \mathrm{CI}, 0.54-1.17$ for the AA genotype and A allele, respectively) (Table IV).

The rs 11031006 FSHB SNP. Genotype and allele frequencies of the FSHB rs11031006 SNP in women with endometriosis and controls are shown in Table $\mathrm{V}$. The results showed a decreased frequency of the GA genotype in patients with 
Table IV. Genotype and allele frequencies of the VEZT rs10859871 polymorphism analyzed in 79 women with endometriosis (stage III and IV) and 150 healthy controls.

\begin{tabular}{|c|c|c|c|c|}
\hline Genotypes/Alleles & Endometriosis & Controls & P-value & OR (95\% CI) \\
\hline Genotypes & $\mathrm{N}=79$ & $\mathrm{~N}=150$ & & \\
\hline AA & $25(31.65 \%)$ & $53(35.33 \%)$ & 0.16 & $0.51(0.29-1.28)$ \\
\hline $\mathrm{AC}$ & $42(53.16 \%)$ & $84(56 \%)$ & 0.18 & $0.54(0.23-1.29)$ \\
\hline $\mathrm{CC}$ & $12(5.19 \%)$ & $13(8.67 \%)$ & & 1.00 (Reference) \\
\hline Alleles & $\mathrm{N}=158$ & $\mathrm{~N}=300$ & & \\
\hline A & $92(58.23 \%)$ & $190(63.33 \%)$ & 0.26 & $0.79(0.54-1.17)$ \\
\hline $\mathrm{C}$ & $66(41.77 \%)$ & $110(36.67 \%)$ & & 1.00 (Reference) \\
\hline
\end{tabular}

OR, odds ratio; CI, confidence interval.

Table V. Genotype and allele frequencies of the FSHB rs 11031006 polymorphism analyzed in 166 women with endometriosis and 150 healthy controls.

\begin{tabular}{|c|c|c|c|c|}
\hline Genotypes/Alleles & Endometriosis & Controls & P-value & OR $(95 \% \mathrm{CI})$ \\
\hline Genotypes & $\mathrm{N}=79$ & $\mathrm{~N}=150$ & & \\
\hline GG & $142(85.54 \%)$ & $114(76.00 \%)$ & & 1.00 (Reference) \\
\hline GA & $24(14.46 \%)$ & $35(23.33 \%)$ & 0.0438 & $0.55(0.31-0.98)$ \\
\hline $\mathrm{AA}$ & $0(0 \%)$ & $1(0.67 \%)$ & 0.4475 & $0.27(0.01-6.64)$ \\
\hline Alleles & $\mathrm{N}=332$ & $\mathrm{~N}=300$ & & \\
\hline $\mathrm{G}$ & $308(92.77 \%)$ & $263(87.67 \%)$ & & 1.00 (Reference) \\
\hline A & $24(7.23 \%)$ & $37(12.33 \%)$ & 0.0316 & $0.55(0.32-0.95)$ \\
\hline
\end{tabular}

OR, odds ratio; CI, confidence interval. Bold, statistically significant difference.

Table VI. Genotype and allele frequencies of the FSHB rs11031006 polymorphism analyzed in 79 women with endometriosis (stage III and IV) and 150 healthy controls.

\begin{tabular}{|c|c|c|c|c|}
\hline Genotypes/Alleles & Endometriosis & Controls & P-value & OR $(95 \% \mathrm{CI})$ \\
\hline Genotypes & $\mathrm{N}=79$ & $\mathrm{~N}=150$ & & \\
\hline GG & $64(81.01 \%)$ & $114(76 \%)$ & & 1.00 (Reference) \\
\hline GA & $15(18.99 \%)$ & $35(23.33 \%)$ & 0.5 & $0.76(0.39-1.50)$ \\
\hline $\mathrm{AA}$ & $0(0 \%)$ & $1(0.67 \%)$ & 1.00 & $0.59(0.02-14.71)$ \\
\hline Alleles & $\mathrm{N}=158$ & $\mathrm{~N}=300$ & & \\
\hline $\mathrm{G}$ & $143(90.51 \%)$ & $263(87.67 \%)$ & & 1.00 (Reference) \\
\hline A & $15(9.49 \%)$ & $37(12.33 \%)$ & 0.44 & $0.74(0.39-1.40)$ \\
\hline
\end{tabular}

OR, odds ratio; CI, confidence interval.

endometriosis compared with controls $(\mathrm{P}=0.0438, \mathrm{OR}=0.55$, 95\% CI, 0.31-0.98), while this difference was also evident for the minor allele $\mathrm{A}(\mathrm{P}=0.0316, \mathrm{OR}=0.55,95 \% \mathrm{CI}, 0.32-0.95)$. No association between this SNP and endometriosis was revealed after an analysis conducted according to stages III/IV of the disease $(\mathrm{P}=0.5, \mathrm{OR}=0.76,95 \% \mathrm{CI}, 0.39-1.50$ and $\mathrm{P}=0.44$, $\mathrm{OR}=0.74,95 \% \mathrm{CI}, 0.39-1.40$ for GA genotype and allele $\mathrm{A}$, respectively) (Table VI).

\section{Discussion}

Although GWAS have detected many endometriosis susceptibility genes, it is clear that there are differences in genetic associations with endometriosis across different world populations (14). Therefore, it is important to study the genetic basis of this condition in multiple populations and replicate previous findings, which would be crucial for some genome-wide 
significant endometriosis risk variants such as rs1859871 in VEZT, rs11031006 in FSHB genetic loci or rs7521902 WNT4. The rs 7521902 was previously shown to yield contradictory results according to ethnic populations analyzed (31). In this study, it was found that AC genotype of rs7521902 SNP is associated with an increased risk for endometriosis in patients of stages III/IV only.

rs7521902 WNT4 SNP has been repeatedly associated with an increased susceptibility for endometriosis in women of different ethnicities, including British, Australian, Italian, and Japanese women (14,27-30). In the present study, no association was detected between the risk allele C of this SNP and increased risk for endometriosis. These data are consistent with those reported previously by Sundqvist et al and Mafra et al $(31,32)$. In particular, no association was observed between the rs7521902 SNP and women of European ancestry, 1,129 with and 831 without endometriosis, analyzed in Belgium (31). Similarly, no association was detected either in a study conducted in 800 Brazilian women (400 with and 400 without endometriosis) (32), or in another one performed in Chinese Han women 646 with and 766 without endometriosis (33). Although this inability of some of the aforementioned studies to confirm previous findings may result from type II errors and may be related to sample size (as stated by the authors), the discrepancy may also be due in some cases to the investigating populations being collected from different endometriosis staging, and more likely, to the variations among ethnicities. However, in the analysis conducted on the Greek patients according to the stage of endometriosis, a genotypic association was detected.

The rs7521902 is an intergenic variant located at 1p36.12 (34). WNT4 encodes for a protein imperative for development of the female reproductive tract, representing a critical, well-known regulator of uterine development (35). In addition, WNT4 has been shown to be expressed in normal peritoneum, suggesting that endometriosis can arise through metaplasia using developmental pathways involved in the development of the female reproductive tract (36). Based on these biological functions, WNT4 has been indicated as a strong candidate for the development of functional changes involved in the endometriosis, considering that WNT4 is expressed in human endometrium during both the proliferative and secretory phases (37). Variants at the $1 \mathrm{p} 36$ chromosomal region, involving the WNT4 gene, may contribute to endometriosis for susceptibility through abnormal cell growth in the female genital tract (32).

The rs10859871 is located in the chromosome $12 \mathrm{q} 22$ region, $17 \mathrm{~kb}$ upstream of the VEZT gene (14). VEZT is a transmembrane protein with a short extracellular and long intracellular domain, which anchors to myosin VIIA as part of the adherent junctional complex in epithelial cells $(38,39)$. In blood and endometrium, the endometriosis risk allele $\mathrm{C}$ of rs10859871 SNP has been associated with an increase in VEZT expression and this aberrant expression of VEZT may be involved in the pathogenesis of endometriosis. Notably, in the present study the allelic effect was in the opposite direction compared to the original GWAS (40).

An association between rs11031006 and endometriosis was detected in the present study. This SNP lies in the 5' region of FSHB (chr 11p14.1), which is involved in sex steroid hormone pathways. FSHB encodes the hormone-specific b-subunit of follicle stimulating hormone (FSH), a key promoter of ovarian follicle growth and oestrogen production. Based on data from the ENCODE project (41), it was found that this SNP alters the sequence of 11 protein-binding motifs including that of the estrogen receptor $\alpha$, thus indicating a possible effect on hormonal feedback inhibition. Recently, allele G of this SNP has been reported to be significantly associated with higher serum FSH levels (42).

As the pathogenesis of endometriosis is highly complex, involving both genetic background and environmental conditions, conflicting studies in several cases have made the interpretation of these data challenging. A definite advantage of our study was the attention paid to the selection of a homogeneous patient cohort and control group. As a consequence, the results are unlikely to be biased by sampling. The major weakness of our study that must be considered when interpreting our results was small sample size due to the lack of a non-invasive method to confirm a diagnosis of endometriosis at the population level. Failure to confirm previous findings is largely attributed to insufficient power, population differences as well as to interaction with genetic and/or non-genetic factors (43). Of note, an important benefit of analyzing genetic associations for different ethnic populations is that it also can shed light on the breakdown of associations due to population differences in linkage disequilibrium. At the genomic level, this 'trans-ethnic fine mapping' is an important method to narrow down the signal towards a causal variant. However, this is less likely to be useful in populations that are similar in common disease variant distributions such as the Greek vs. other European ancestry populations. Further exploration of the loci by assaying surrounding variants, such as through GWAS, is required to test this aspect.

In conclusion, the results from this study demonstrate the necessity of GWAS in larger sample sizes to reveal and/or confirm genetic variants associated with endometriosis in the Greek population. Our data emphasize the importance of assessing genetic variants in different populations, even within Europe, in an attempt to define the genetic architecture of endometriosis and the magnitude of the effects of specific risk alleles in different populations. Functional studies are required to elucidate the exact contribution of the variants analyzed in endometriosis risk.

\section{Acknowledgements}

We would like to thank all the practitioners for providing the data and pathology reports used in the present study. This study was supported partially by a grant by ELKE (KA 4462, University of Crete) to G.N.G. K.Z. has scientific collaborations in the area of endometriosis with Bayer AG (Leverkusen, Germany), Roche Diagnostics (Basel, Switzerland), and MDNA.

\section{References}

1. Halis $\mathrm{G}$ and Arici A: Endometriosis and inflammation in infertility. Ann N Y Acad Sci 1034: 300-315, 2004.

2. Burney RO and Giudice LC: Pathogenesis and pathophysiology of endometriosis. Fertil Steril 98: 511-519, 2012.

3. Simpson JL, Elias S, Malinak LR and Buttram VC Jr: Heritable aspects of endometriosis. I. Genetic studies. Am J Obstet Gynecol 137: 327-331, 1980.

4. Lamb K, Hoffmann RG and Nichols TR: Family trait analysis: A case-control study of 43 women with endometriosis and their best friends. Am J Obstet Gynecol 154: 596-601, 1986. 
5. Coxhead D and Thomas EJ: Familial inheritance of endometriosis in a British population. A case control study. J Obstet Gynaecol 13: 42-44, 1993.

6. Moen MH and Magnus P: The familial risk of endometriosis. Acta Obstet Gynecol Scand 72: 560-564, 1993.

7. Stefansson H, Geirsson RT, Steinthorsdottir V, Jonsson H, Manolescu A, Kong A, Ingadottir G, Gulcher J and Stefansson K: Genetic factors contribute to the risk of developing endometriosis. Hum Reprod 17: 555-559, 2002.

8. Treloar SA, O'Connor DT, O'Connor VM and Martin NG: Genetic influences on endometriosis in an Australian twin sample.sueT@ qimr.edu.au. Fertil Steril 71: 701-710, 1999.

9. Saha R, Pettersson HJ, Svedberg P, Olovsson M, Bergqvist A, Marions L, Tornvall P and Kuja-Halkola R: Heritability of endometriosis. Fertil Steril 104: 947-952, 2015.

10. Zondervan KT, Weeks DE, Colman R, Cardon LR, Hadfield R, Schleffler J, Trainor AG, Coe CL, Kemnitz JW and Kennedy SH: Familial aggregation of endometriosis in a large pedigree of rhesus macaques. Hum Reprod 19: 448-455, 2004.

11. Sampson J: Endometrial carcinoma of the ovary, arising in endometrial tissue in that organ. Arch Surg 10: 1-72, 1925

12. Falconer H, D'Hooghe T and Fried G: Endometriosis and genetic polymorphisms. Obstet Gynecol Surv 62: 616-628, 2007.

13. Sapkota Y, Steinthorsdottir V, Morris AP, Fassbender A, Rahmioglu N, De Vivo I, Buring JE, Zhang F, Edwards TL, Jones S, et al; iPSYCH-SSI-Broad Group: Meta-analysis identifies five novel loci associated with endometriosis highlighting key genes involved in hormone metabolism. Nat Commun 8: $15539,2017$.

14. Rahmioglu N, Nyholt DR, Morris AP, Missmer SA, Montgomery GW and Zondervan KT: Genetic variants underlying risk of endometriosis: Insights from meta-analysis of eight genome-wide association and replication datasets. Hum Reprod Update 20: 702-716, 2014.

15. Sapkota Y, Attia J, Gordon SD, Henders AK, Holliday EG, Rahmioglu N, MacGregor S, Martin NG, McEvoy M, Morris AP, et al: Genetic burden associated with varying degrees of disease severity in endometriosis. Mol Hum Reprod 21: 594-602, 2015.

16. Zondervan KT, Rahmioglu N, Morris AP, Nyholt DR Montgomery GW, Becker CM and Missmer SA: Beyond endometriosis genome-wide association study: From genomics to phenomics to the patient. Semin Reprod Med 34: 242-254, 2016

17. Costa IR, Silva RC, Frare AB, Silva CT, Bordin BM, Souza SR, Ribeiro Júnior CL and Moura KK: Polymorphism of the progesterone receptor gene associated with endometriosis in patients from Goiás, Brazil. Genet Mol Res 10: 1364-1370, 2011.

18. Altinkaya SO, Ugur M, Ceylaner G, Ozat M, Gungor T and Ceylaner S: Vascular endothelial growth factor $+405 \mathrm{C} / \mathrm{G}$ polymorphism is highly associated with an increased risk of endometriosis in Turkish women. Arch Gynecol Obstet 283: 267-272, 2011

19. Bau DT, Hsieh YY, Wan L, Wang RF, Liao CC, Lee CC, Lin CC, Tsai CH and Tsai FJ: Polymorphism of XRCC1 codon arg 399 Gln is associated with higher susceptibility to endometriosis. Chin J Physiol 50: 326-329, 2007.

20. Hsieh YY, Bau DT, Chang CC, Tsai CH, Chen CP and Tsai FJ: XRCC4 codon $247^{*} \mathrm{~A}$ and XRCC4 promoter $-1394^{*} \mathrm{~T}$ related genotypes but not XRCC4 intron 3 gene polymorphism are associated with higher susceptibility for endometriosis. Mol Reprod Dev 75: 946-951, 2008

21. Eliopoulos E, Zervou MI, Andreou A, Dimopoulou K, Cosmidis N, Voloudakis G, Mysirlaki H, Vazgiourakis V, Sidiropoulos P, Niewold TB, et al: Association of the PTPN22 R620W polymorphism with increased risk for SLE in the genetically homogeneous population of Crete. Lupus 20: 501-506, 2011

22. Zervou MI, Vazgiourakis VM, Yilmaz N, Kontaki E, Trouw LA, Toes RE, Bicakcigil M, Boumpas DT, Yavuz S and Goulielmos GN: TRAF1/C5, eNOS, Clq, but not STAT4 and PTPN22 gene polymorphisms are associated with genetic susceptibility to systemic lupus erythematosus in Turkey. Hum Immunol 72: 1210-1213, 2011.

23. Dimopoulou DG, Zervou MI, Trachana M, Myrthianou E, Pratsidou-Gertsi P, Kardassis D, Garyfallos A and Goulielmos GN: Investigation of juvenile idiopathic arthritis susceptibility loci: Results from a Greek population. Hum Immunol 74: 1194-1198, 2013

24. Zervou MI, Myrthianou E, Flouri I, Plant D, Chlouverakis G, Castro-Giner F, Rapsomaniki P, Barton A, Boumpas DT, Sidiropoulos P and Goulielmos GN: Lack of association of variants previously associated with anti-TNF medication response in rheumatoid arthritis patients: results from a homogeneous Greek population. PLoS One 8: e74375, 2013.
25. Goulielmos GN, Chiaroni-Clarke RC, Dimopoulou DG, Zervou MI, Trachana M, Pratsidou-Gertsi P, Garyfallos A and Ellis JA: Association of juvenile idiopathic arthritis with PTPN22 rs2476601 is specific to females in a Greek population. Pediatr Rheumatol Online J 14: 25, 2016.

26. The American Fertility Society: Revised American Fertility Society classification of endometriosis: 1985. Fertil Steril 43: 351-352, 1985.

27. Nyholt DR, Low SK, Anderson CA, Painter JN, Uno S, Morris AP, MacGregor S, Gordon SD, Henders AK, Martin NG, et al: Genome-wide association meta-analysis identifies new endometriosis risk loci. Nat Genet 44: 1355-1359, 2012.

28. Uno S, Zembutsu H, Hirasawa A, Takahashi A, Kubo M, Akahane T, Aoki D, Kamatani N, Hirata K and Nakamura Y: A genome-wide association study identifies genetic variants in the CDKN2BAS locus associated with endometriosis in Japanese. Nat Genet 42: 707-710, 2010.

29. Painter JN, Anderson CA, Nyholt DR, Macgregor S, Lin J, Lee SH, Lambert A, Zhao ZZ, Roseman F, Guo Q, et al: Genome-wide association study identifies a locus at 7p15.2 associated with endometriosis. Nat Genet 43: 51-54, 2011.

30. Pagliardini L, Gentilini D, Vigano' P, Panina-Bordignon P, Busacca M, Candiani M and Di Blasio AM: An Italian association study and meta-analysis with previous GWAS confirm WNT4, CDKN2BAS and FN1 as the first identified susceptibility loci for endometriosis. J Med Genet 50: 43-46, 2013.

31. Sundqvist J, Xu H, Vodolazkaia A, Fassbender A, Kyama C, Bokor A, Gemzell-Danielsson K, D'Hooghe TM and Falconer H: Replication of endometriosis-associated single-nucleotide polymorphisms from genome-wide association studies in a Caucasian population. Hum Reprod 28: 835-839, 2013.

32. Mafra F, Catto M, Bianco B, Barbosa CP and Christofolini D: Association of WNT4 polymorphisms with endometriosis in infertile patients. J Assist Reprod Genet 32: 1359-1364, 2015.

33. Wu Z, Yuan M, Li Y, Fu F, Ma W, Li H, Wang W and Wang S: Analysis of WNT4 polymorphism in Chinese Han women with endometriosis. Reprod Biomed Online 30: 415-420, 2015.

34. Luong HTT, Painter JN, Shakhbazov K, Chapman B, Henders AK, Powell JE, Nyholt DR and Montgomery GW: Fine mapping of variants associated with endometriosis in the WNT4 region on chromosome 1p36. Int J Mol Epidemiol Genet 4: 193-206, 2013

35. Vainio S, Heikkilä M, Kispert A, Chin N and McMahon AP: Female development in mammals is regulated by Wnt-4 signalling. Nature 397: 405-409, 1999.

36. Gaetje R, Holtrich U, Engels K, Kissler S, Rody A, Karn T and Kaufmann M: Endometriosis may be generated by mimicking the ontogenetic development of the female genital tract. Fertil Steril 87: 651-656, 2007

37. Bui TD, Zhang L, Rees MCP, Bicknell $\mathrm{R}$ and Harris AL: Expression and hormone regulation of Wnt2, 3, 4, 5a, 7a, 7b and $10 \mathrm{~b}$ in normal human endometrium and endometrial carcinoma. Br J Cancer 75: 1131-1136, 1997.

38. Küssel-Andermann P, El-Amraoui A, Safieddine S, Nouaille S, Perfettini I, Lecuit M, Cossart P, Wolfrum U and Petit C: Vezatin, a novel transmembrane protein, bridges myosin VIIA to the cadherin-catenins complex. EMBO J 19: 6020-6029, 2000.

39. Blaschuk OW and Rowlands TM: Plasma membrane components of adherens junctions (Review). Mol Membr Biol 19: 75-80, 2002.

40. Holdsworth-Carson SJ, Fung JN, Luong HT, Sapkota Y, Bowdler LM, Wallace L, Teh WT, Powell JE, Girling JE, Healey M, et al: Endometrial vezatin and its association with endometriosis risk. Hum Reprod 31: 999-1013, 2016.

41. Dunham I, Kundaje A, Aldred SF, Collins PJ, Davis CA, Doyle F, Epstein CB, Frietze S, Harrow J, Kaul R, et al; ENCODE Project Consortium: An integrated encyclopedia of DNA elements in the human genome. Nature 489: 57-74, 2012.

42. Mbarek H, Steinberg S, Nyholt DR, Gordon SD, Miller MB, McRae AF, Hottenga JJ, Day FR, Willemsen G, de Geus EJ, et al: Identification of common genetic variants influencing spontaneous dizygotic twinning and female fertility. Am J Hum Genet 98: 898-908, 2016.

43. Ma L, Brautbar A, Boerwinkle E, Sing CF, Clark AG and Keinan A: Knowledge-driven analysis identifies a gene-gene interaction affecting high-density lipoprotein cholesterol levels in multi-ethnic populations. PLoS Genet 8: e1002714, 2012. 